\title{
Teaching Outdoor Adventure Activities in \\ Preschools: A Review of Creativity and Learning Development
}

\author{
Aglaia Zafeiroudi (Corresponding author) \\ Department of Physical Education and Sport Science \\ University of Thessaly, Karies, Trikala, 42100, Greece \\ Tel.: +30-243-104-7004Ｅ-mail: aglaiazaf@hotmail.com
}

\begin{abstract}
Charilaos Kouthouris
Department of Physical Education and Sport Science

University of Thessaly, Karies, Trikala, 42100, Greece
\end{abstract}

Tel.: +30-243-104-7004Ｅ-mail: kouthouris@pe.uth.gr

Received: June 6, 2021 Accepted: June 18, $2021 \quad$ Published: June 21, 2021

doi:10.5296/ijld.v11i2.18722 URL: https://doi.org/10.5296/ijld.v11i2.18722

\begin{abstract}
Creativity is a significant part of all aspects of childhood growth and development, including learning. Adventure play has been identified as a key component of early childhood, and it presents a variety of challenges and opportunities to educators, parents and children. This study explores the current state of knowledge of preschool outdoor adventure activity teaching and its impact on learning and creativity. The review reveals that adventure play boosts creativity and learning development in preschool children. Through a review of current literature, this paper discusses the importance of adventure activities in early years, the role of risk in creativity and learning development and the appropriateness of outdoor and adventure activity teaching methods. The paper concludes with an examination of gaps in existing knowledge and a discussion of the challenges to outdoor adventure activities from both parents and children. It recommends that schools, kindergartens and other institutions organize events, such as conferences, to educate parents and teachers on the role of outdoor
\end{abstract}


adventure play in enhancing children's learning abilities and creative thinking.

Keywords: outdoor play, risk, natural sciences, physical activities, environment, drama, storytelling.

\section{Introduction}

Adventure activities entail outdoor practices that children undertake under the guidance of their carers or educators. According to Y1ldirım and Akamca (2017), learning can occur outside the classroom in places such as zoos, museums, aqua parks, botanical gardens, forests, playgrounds, and rivers. Therefore, adventure education is an aspect of education that takes place outside the classroom. Yildirım and Akamca (2017) note that outdoor education provides preschool children with opportunities to perceive the world from different perspectives. Children can benefit from interactions with nature, supported by outdoor play. When engaged in adventure education, young children can learn about different aspects of nature as they try to understand the world and what they encounter in the world (Zafeiroudi, 2020; Zafeiroudi, 2014; Zafeiroudi, \& Hatzigeorgiadis, 2014; Garitsis et al., 2010; Zafeiroudi $\&$ Hatzigeorgiadis, 2008). According to Torkar and Rejc (2017), patterns of behaviour, values and attitudes towards nature are shaped during early childhood. Through active participation, children can acquire fundamental concepts about the environment. Adventure play includes activities such as water play, dramatic play, playing with blocks and visiting science centres. For example, the provision of a water table can provide sensory fun. Sand can be added to the water table and the children can make mud. Dramatic play may involve cooking on a rock as a substitute for an oven. The addition of a variety of blocks can provide children with opportunities for outdoor construction. Therefore, outdoor activities encourage children to be more creative and to develop their learning proficiencies. Exposing children to both classroom and outdoor environments seems to be crucial for the development of learning and to enhancing creativity.

\section{Objectives of the Study}

This paper explores the current state of knowledge regarding the use of adventure activities among preschool children and the impact of these activities on the enhancement of learning and creativity. Past literature is used to support the current knowledge. The paper discusses the importance of adventure activities in the early years, and the role these activities play in creativity and learning development, with supporting evidence from relevant current literature.

\section{Adventure Activities in Early Childhood}

Adventure activities benefit preschool children in various ways. According to Frost and Sutterby (2017), a recognition of the importance of outdoor play can be traced back to Friedrich Froebel who created materials that could be utilized in outside activities that enhanced childhood development through nature. Erdem (2018) argues that planned field trips to national parks, forests or botanical gardens contribute significantly to cognitive and emotional learning. Such experiences facilitate involvement as they encourage children to ask questions related to the outdoor environment to which they are exposed. Inquiries arising out 
of curiosity help children to engage their imaginative skills as they think about what to ask with regard to what they are experiencing in the environment. Adventure activities and play expose preschool children to hands-on experiences, observations and the use of multiple sensory systems, all of which promote learning and cognitive processing. Shepley et al. (2018) have found that children who do not participate in outside activities may experience developmental delays. This section highlights the benefits to preschool children of learning and creativity while engaged in adventure activities.

The outdoor environment can inspire children to be curious about nature as they seek to find out more about what they see. According to Bento and Dias (2017), the open-ended possibilities of natural materials encourage children to be imaginative as they offer countless possibilities for play. For instance, children can endeavour to assign new meanings and interpretations to objects, in a process of reinvention. A natural object, such as a stick, for example, can be assigned the characteristics and purpose of a gun. This highlights how creativity can be enabled when children are exposed to natural materials. Therefore, adventure activities promote a child's desire to understand and innovate the use and purpose of objects, thus improving their learning capabilities.

Adventure play also promotes crucial aspects of early childhood education. According to Bento and Dias (2017), playing with water and soil is beneficial to children, as it provides them with opportunities to learn concepts related to science and mathematics. Furthermore, language acquisition is promoted through play with soil and water, as children share the new vocabulary they learned in the course of their endeavours. For instance, as children fill and empty containers with soil and water, they start to become familiar with concepts related to volume, weight and time. In this game of filling and emptying containers multiple times, children learn mathematical and scientific concepts, without being aware that they are learning. Therefore, adventure activities provide children with opportunities to learn from an early age, which improves their chances of success in adulthood.

Participation in schoolyard activities exposes children to practices that encourage creativity and learning. According to previous literature, field trips to places such as national parks and forests improves cognitive and emotional learning (Rennie \& McClafferty, 1996). Children are encouraged to actively participate in outside activities when they are exposed to nature. Mycock (2020) points out, for instance, that children have more curiosity and ask more questions when they are taken on nature than when they are in the classroom. However, it is crucial that learners are prepared for such trips in advance in order to be better focused on the details of the environment they visit. Other researchers acknowledge that green schoolyard activities provide children with the chance to witness "hands-on-concrete experiences" and to observe the world around them, thus promoting cognitive learning and processing through the use of multiple sensory systems (van Dijk-Wesselius, van den Berg, Maas, \& Hovinga, 2020). Such learning opportunities include exposing children to natural processes, such as observing the life cycle of butterflies.

Van Dijk-Wesselius et al. (2020) note that schoolyard activities foster scientific learning by supporting proficiencies such as measuring, finding creative solutions, designing and 
conducting research and problem-solving. These are crucial skills for excelling in science and mathematics. Furthermore, Erdem (2018) reveals that teachers can make use of schoolyard animals and plants to teach challenging mathematical concepts. For example, students can be taught how to measure weekly or monthly plant growth and make graphs or charts of that growth.

According to other study, schoolyard activities improve cognitive skills such as recalling information, classification, and naming (Kinzie et al., 2014). These aptitudes enhance creativity, as the activities carried out in the schoolyard foster advanced cognitive function, such as evaluation based on provided criteria, testing, planning, problem solving and the use of evidence to support arguments. The involvement of parents and others, such as peers, in schoolyard play and learning supports children's achievements (Erdem, 2018). In addition, parents play an essential role in increasing children's self-esteem, peer cooperation and teamwork, all of which are critical to building relationships between children. Erdem (2018) notes that other studies have found that students feel proud of their achievements when they are involved in outdoor activities, such as those that take place in the schoolyard. Therefore, children benefit from such environments through improvements to their cognitive and other skills that provide the foundations for becoming successful learners as they transition into adulthood.

Involvement in risk-taking play also contributes to childhood development. Risk-taking plays an essential role in children's satisfaction and wellbeing and contributes to the development of life and academic skills (Gull et al., 2018). During risky play situations, children must engage their powers of recognition, evaluation, and decision-making. In this case, the child has to recognize the risk, evaluate the available options and mindfully elect the next course of action. Putting children in situations that necessitate decision-making enhances the learning process by providing them with opportunities to think widely about what course of action to take based on the consequences associated with each action taken. Gull et al. (2018) affirm that children take risks when engaged in natural play, and that they use creativity as they develop emotional, physical, manual dexterity, imaginative and cognitive skills.

Learning through trial and error also helps children to develop proficiency in critical thinking and problem-solving. According to Gull et al. (2018), adventure activities, such as tree climbing, encourage inspiration and creativity. Outdoor activities help young children to improve their spatial awareness during the early stages of motor development. When climbing trees, different tree heights provide children with opportunities to negotiate risks and challenges. Therefore, children can significantly benefit from their involvement in different forms of adventure play, some of which present manageable risks.

Researchers have distinguished four levels of creativity establishing the Four-C model (Kaufman \& Beghetto, 2009). The four components of the model are mini-c (personal creativity), little-c (everyday creativity), Pro-C (expert creativity) and Big-C (genius creativity). In education the four $\mathrm{C}$ represents critical thinking, communication and collaboration. According to Wojciehowski and Ernst (2018), little-c and mini-c creativity are vital in the development of creative thinking in young children, with the emphasis on mini-c 
creativity. These authors also acknowledge the essential role of play in helping young children to learn about the world and about themselves. Certain aspects of knowledge can only be acquired through play and cannot be taught in a classroom setting or elsewhere. One strategy to assist young children in achieving mini-c creativity is to provide opportunities for child-directed and self-initiated play, allowing children to organically construct knowledge through play experiences. Moreover, pretending during play develops numerous thought processes, such as flexibility, divergent thinking and perspective-taking (Wojciehowski \& Ernst, 2018). Little-c creativity, meanwhile, can be attained by providing time for exploration and play in domain-specific skills. Wojciehowski and Ernst (2018) argue that educators should emphasize little-c and mini-c creativity to help children to develop proficiency in lifelong creative thinking abilities.

Movement play during outdoor play sessions encourages children to practice gross and fine motor skills. Kroeker (2017) argues that outdoor and indoor play can be complementary, as each environment exposes children to different conditions. Kroeker (2017) also highlights the significance of child-initiated play to promote skill development. The development of motor skills benefits children in the long run in several ways. According to McClelland and Cameron (2019), executing the physical movements required for learning necessitates deliberation and planning. Gross and fine motor skills support school functioning, with visuomotor and fine motor proficiency leveraged in preschool in the gripping of pencils and crayons, the handling of materials and paper and symbol recognition. As McClelland and Cameron (2019) assert, visuomotor skills, which involve the coordination of motor movements with visual perception, are positively linked to mathematics and literacy outcomes.

During outdoor play, children are exposed to challenges and risks as they navigate natural objects and materials. Harper (2017) argues that contemporary society is accustomed to ever-growing and ever-present risk perception, leading to significant restrictions on outdoor play. Risk can be defined as any exposure to danger that is likely to result in loss, harm or gain. Harper (2017) defines risky play as "a set of motivated behaviours that both provide the child with an exhilarating positive emotion and expose the child to the stimuli" which the child may have avoided, been fearful of or never have had the opportunity to try. Adventure environments that may present a risk to learners include forest and nature schools.

The risks and challenges to which children are exposed during adventure play are crucial to the development of creativity and learning. According to Harper (2017), forest and nature schools provide children with the opportunity to reconnected with nature, allowing the establishment of a sense of place that facilitates development and growth. Playing in environments that are considered risky can help children to reduce their inhibitions and address developmental phobias through repeated and increasingly challenging experiences. Harper (2017) notes that creativity increases with the amount of time a child spends playing outdoors. However, adults should minimize their involvement and supervision of play, as natural and green playgrounds are considered more restorative, allowing children to create their games and have fun. During outdoor activities, children experience a mixture of excitement and fear and demonstrate self-monitoring behaviours as they engage in and avoid 
risk, creating pleasure and enjoyment.

Gull et al. (2018) define resilience as having the necessary strength to tackle challenges. This implies that resilience may be attained when participating in practices that threaten development and adaptation but result in desirable outcomes. Resilience encompasses traits such as independence, initiative, insight, humour, creativity, relationships and morality (Gull et al. 2018). A resilient child exhibits problem solving skills, social competence, a sense of future, purpose and autonomy. Gull et al. (2018) insist that tree climbing can equip children with these traits. Therefore, despite the risks involved in adventure activities such as tree climbing, the benefits associated with such endeavours outweigh the concerns.

When children are constantly guided by adults and not exposed to risky situations, they may lack opportunities to practice decision-making. According to McFarland and Laird (2018), risky circumstances allow children to decide which types of risk they can handle, and which might prove problematic. In this way, children learn assessment skills as they evaluate the situation before taking the next step. These authors (2018) further note that children learn new life skills while having fun in risky play situations. For instance, a child may experience failure due to a certain decision. However, this failure has positive implications as it gives the child the opportunity to consider different ways to approach the problem now and in the future. McFarland and Laird (2018) acknowledge that learning from failure helps children to develop a sense of motivation to master novel challenges and achieve their objectives. Therefore, risky activities and the challenges children face during such play promotes creativity and enhances learning through processes of decision-making that lead to both failure and success.

\section{Teaching Methods and Good Practices}

Educators use a variety of methods to engage children in adventure education in the outdoor environment. The strategies that educators adopt are based on the premise that preschool outdoor activities should be child-led and should benefit children as they transition from home to school. Methods include storytelling, play, nature journals, alphabet activities, play with unstructured materials and the use of pavement chalk.

Storytelling is a common early childhood teaching strategy (Wright, Diener \& Kemp, 2013). Davies (2020) asserts that storytelling is a crucial aspect of nature play as stories enhance children's understanding of the outdoor environment. Stories help humans to understand the world and the elements within the world. Indeed, human lives are lived by continuous narrative (Davies, 2020). This implies that the cognitive processes underlying music and stories are inherent in humans, thus explaining why children tell and use stories to shape their play. During adventure activities, the characters involved in the stories told to children include rocks, plants, animals, and the landforms that characterize the adventure environment. Furthermore, children themselves can become characters in such narratives, with the setting of the story creating the outdoor environment to be explored. Based on the theory of constructivism, digital and interactive storytelling has been used to enhance thinking and provide an effective learning environment for natural science courses (Jui-Feng Weng, Hsiu-lien Kuo, \& Shian-Shyong Tseng, 2011; Rahiem, 2021). 
Educators also use play as a method in outdoor educational activities. Through play in an adventure environment, children can accomplish what the educator intends and can be directed to engage in different forms of play meant to achieve specific objectives. Sociodramatic play, for example, motivates children to engage with peers and to practice skills such as negotiation and communication. Another example is jumping relay, which begins with children forming rows. Three children then jump as fast as they can until they reach the turning point and then return to the line (Sørensen \& Birkeland, 2020). The teacher categorizes the children into three clusters and demonstrates how they were supposed to jump. The playful atmosphere inspires laughter, as the children enjoy the game without understanding what the game is trying to achieve.

Educators can also use nature journaling to teach adventure activities. According to Gardoqui and Haeger (2020), nature journaling is a way to practice descriptive and observation skills. Children can use journals to record their observations, sketches and the wonders of nature. For preschool children, journals provide appropriate material to sketch or write what they feel is relevant as they observe the natural environment around them. Even though adults may not understand or be able to interpret the children's drawing, the activity provides the children with the opportunity to connect to what they see by attempting to record it in a journal in some way (Gardoqui \& Haeger, 2020).

Preschool teachers can also effectively use an alphabet activity while outdoors. This activity is a fun way for children to practice letter formation. It gives children the chance to recognize letters by playing with them as they attempt to form meaningful words. Additional materials, such as water buckets can be used to help children recognize words by sight. Here, the child can splash the sight word with water and have fun finding the words that have been affected by the water. Using this approach, teachers can develop an understanding of the different visual capabilities of the children in their care.

Educators guiding outdoor adventures can make mathematics more interesting by adopting strategies that keep children focused. Kaplan (n.d.) explains a pavement activity in which the teacher asks the children to take a stick of pavement chalk and then spread out. Each child is assigned a number that will be written on the pavement with the chalk. The numbers are large enough to be seen from a distance. The teacher then calls out the numbers, one by one, and the children run to each number as they hear it. This can be a successful activity if the teacher gives the children prior instructions to guide their responses in different circumstances. For instance, when a certain number is called out, all the participants are expected to run in the direction of that number. As learning progresses, with the assistance of the teacher, the children can even start calling the numbers themselves. This teaching method exposes children to some critical aspects of mathematics.

According to Cordiano et al. (2019), nature-based programmes provide children with opportunities to engage with unstructured materials, including rocks, dirt, leaves and sticks. Children do not have to be told what to do with these unstructured materials. Through imaginative play, children can transform these unstructured materials into whatever new objects they can think of. This approach enhances creativity and problem-solving skills as 
children learn to be imaginatively flexible in thinking of new things to do with these materials. For example, stick shelters might be transformed into a grocery store one day and into a rocket ship the next (Cordiano et al., 2019). This demonstrates the expansive use of unstructured materials to generate ideas that are beneficial to childhood growth and development as children transition from the home to the school environment.

\section{Challenges, Obstacles, Gaps, and Problems}

Educators may face challenges when engaging preschool children in activities that promote learning development and creativity. In multicultural environments, for example, teachers may find the creation of social interactions between the children difficult (Csánya, 2018), meaning that creative and learning development activities that require cooperation and social interaction cannot be enacted as planned. Outdoor teaching can also be constrained by personal challenges. Children may respond very differently to specific challenges, such as climbing a steep rock or crossing rushing water (McClain, 2017). The role of the teacher in situations such as these is to ensure that the children have the freedom to explore the natural environment and discover unfamiliar aspects of that environment. Therefore, the use of play as a teaching method presents challenges and opportunities for both teachers and preschool children.

Some limitations in the use of outdoor activities in preschool education have been identified. Hunter et al. (2020) argue that educators do not have sufficient time and adequate conversations regarding the preparation and planning of outdoor learning. Many educators believe that more time is required to prepare for indoor activities compared to outdoor play. This is related to the notion that, during adventure activities, teachers have the opportunity to take a break while the children in their care play (Hunter et al., 2020). The lack of coordination and discussion concerning adventure learning demonstrates a lack of connection between the major stakeholders responsible for steering and supporting outside play. Therefore, common understanding is required among educators of the role of applied outdoor teaching methods in the development of creativity and learning among preschool children.

Some parents perceive outdoor activities as risky for their children. Some outdoor play is dangerous and may cause harm to children. Therefore, some parental concern about risk is justified. However, Cortinez-O'Ryan et al. (2017) have found that mothers in developed and industrialized countries worry more about the safety of their children than mothers in developing nations. A study by Tandon et al. (2017) found that, despite parents and child-care providers having similar thoughts about the significance of adventure play, parents place less value on outside play than child-care providers. This difference should be addressed to ensure that parents have a clear understanding of the benefits of adventure play. Educators should encourage the involvement of parents in outdoor activities, thus providing preschool children with the collective benefits of physical activity and outside play. O'Brien et al. (2018) emphasize that childcare environments improve the activity levels of young children. In addition, parents should be made aware that early childhood scholarship supports risky play, as the benefits of risk outweigh the concerns. 


\section{Discussion}

The review reveals that adventure play can boost the development of creativity and learning among preschool children. Wojciehowski and Ernst (2018) identify creative thinking as a key social skill that contributes to advancement in the arts and sciences, to everyday intelligence, social interactions, business innovation and public policy. The underlying characteristic of creative learning is the ability to recognize patterns, find and solve problems, combine information in novel ways, make decisions and seek new ideas while challenging assumptions. Creative thinking traits are essential to effective communication, and to the development, refinement and implementation of ideas. Gershon and Pellitteri (2018) note that the development of emotional intelligence during early childhood is vital in both academic and interpersonal domains.

Creative thinkers are open to new perspectives, they understand the limits of the real world, they demonstrate originality, and they view failure as an opportunity (Wojciehowski \& Ernst, 2018). The benefits of creativity and imaginative thinking in early childhood cannot be understated as they serve as foundational skills to all future learning. Therefore, creativity is a significant aspect of a child's growth and development. Although adventure play has been identified as a key component of early childhood development and education, it presents both challenges and opportunities to educators and children. These challenges can be addressed when all stakeholders embrace the idea that outdoor play is a means to promote wellbeing and learning skills.

Children have a positive regard for outdoor activity, preferring to be outside than in the classroom. The desire to learn from the outside environment encourages children to explore as many details as they can from the setting at their disposal. Children's preferences for outside learning are consistent with general perceptions that the outdoors provides a useful environment for play (Ernst, 2018). This implies that children love to play. Educators should bear this in mind when devising ways to ensure that they support children in their adventure activities.

Ernst (2018) points out that children demonstrate a notable preference for different types of outside environments. Some children opt for adventure grounds with less grass and fewer rocks, trees and puddles. This suggests that stakeholders in this sector must listen to children and create environments appropriate to their needs. Since most activities are child-led, it is imperative that teachers and parents work together to meet children's outdoor play preferences.

Successful outcomes show that the outdoor play methods employed by teachers work well. For instance, soil and water play that enhances creativity expands the minds of children, helping them to think in ways they may not have considered before. Indecision places children in situations in which they must explore and devise choices that may be either harmful or beneficial. Early exposure to decision-making encourages responsibility at an early age, as the choices made have consequences. For instance, a child is unlikely to repeat an incorrect choice, especially when that choice results in dire consequences. 
Methods such as storytelling attract the attention of children and help them to deal with concerns and questions. Through storytelling, teachers can closely connect with preschool learners who actively engage in the conversation by asking questions out of curiosity and for clarification. However, children from multicultural backgrounds pose a challenge to teachers in their attempts to enhance social interactions through approaches such as storytelling. Because some children are unfamiliar with the language of the classroom, teachers find it difficult to create a common language platform for all children. Despite such challenges, storytelling is, in general, a productive way to educate children in the outdoor environment, providing opportunities to listen, comment and react as they want.

Another teaching approach, the use of nature journals, may have some limitations. Given that preschool children do not yet know how to write, nature journals may fail to provide an appropriate platform to express what they have learned. Although journals provide sufficient space for children to record their encounters, the recorded information may not be understood by teachers and, therefore, cannot contribute to the learning development of the children in their care.

Challenges can be expected in any activity. However, success or failure is determined by how those challenges are met. This review has revealed the challenges inherent in adventure activities. These must be addressed in order to improve preschool outdoor teaching. Some of the challenges are highlighted below.

The different activities and time allocated to outdoor play demonstrate a lack of guidance regarding what outdoor play should entail. Some educators consider outdoor play time as their own break time. This implies a lack of emphasis on and attention to what children should engage and participate in while outdoors. If children are left to play alone in the absence of observation and guidance, their educator cannot learn their play patterns. These patterns are crucial to understanding the strengths and weaknesses of each individual child and give the educator insight into the support a child may need to achieve a specific task or goal. The educator can also identify the ways in which individual children can be assisted to improve the skills they exhibit.

Furthermore, appropriate policy guidance will clearly set out the teacher's role in ensuring that no child misses out on early childhood learning opportunities while involved in adventure activities. Although child-led play offers the best opportunity for the development of creativity, the role of the teacher in providing general guidance is imperative. Therefore, existing outdoor play policies must be reassessed in order to assure teachers and parents of the value and appropriateness of adventure activities in early childhood education.

According to Andrew et al. (2019), different approaches to improving the quality of early childhood education yield different results. Steps can be taken to address the challenges facing the entire concept of adventure play. All stakeholders must be brought on board to share a common vision of the preschool curriculum. In this case, stakeholders include parents, tutors, policymakers and children. However, the role of children in such deliberations will be nominal as they are not yet at an age to comprehend or offer meaningful contributions to any debate. Through the collaboration of stakeholders, appropriate mechanisms can be 
established to promote the participation of children in outside activities.

Institutions can play a leading role in convincing parents of the value of outdoor activities. For example, conferences can be organized to educate parents and provide them with information about the contribution of adventure play to the development of learning abilities. Changing parents' perceptions can make them strong advocates for adventure play, given that they are their children's primary guardians. According to Lindsay et al. (2017), the behaviour of parents is a crucial determinant of the conduct of children. In this case, the children of more physically active parents are more likely to embrace the same behaviour of engaging in physical activities during adventure play. At the same time, parents who view physical activity negatively are more likely to discourage their children from engaging in outdoor activities.

This suggests the importance of engaging parents in outside activities because of the impact they have on their children. However, some may argue against parental influence, given that preschool children spend most of their time with their teachers while in the school environment. This is only partly relevant because, outside of the school environment, children spend a significant amount of time with their parents. Therefore, if a parent instils negative thoughts in a child about outdoor play, the child is likely to carry that advice to school and show reluctance in participating in play outside the classroom. In addition, the neighbourhood from which the parent originates may promote positive attitudes concerning outdoor play. According to Xu et al. (2017), certain neighbourhoods exhibit characteristics such as walkability, road safety, recreation facilities and population density.

Parents may be discouraged from allowing their children to participate in risky outdoor play. However, risky play provides children with opportunities to demonstrate what they know in a given situation. Convincing parents of the value of risky play may require a combination of education and legislation. One way to instil confidence in parents is through clearly set out policies that detail how educators will handle risk during outdoor play activities. When it comes to the well-being of children, parents are the most important stakeholders and, therefore, must be convinced that the school has the best interests of the children at heart when exposing them to manageable risks. Through planned educational conferences, educators can explain the protocols they will follow and the actions they will take when children are engaged in risky play, such as tree climbing. Achieving consensus on the importance of adventure play is important, as learning development and creativity are inherent in risky play.

The environments in which children play can either encourage or discourage creativity and learning. Outdoor play environments should be designed to promote innovative thinking. A study of teachers' involvement in different settings found different degrees of teacher participation (Brussoni et al., 2017). It is important to remember that teachers form part of the environment in which children conduct their outdoor activities. Teachers can, therefore, promote play by ensuring the play environment, whether schoolyard or forest, is equipped with the necessary amenities that children can engage with to test their abilities. Therefore, the current gap in adult responsibility results in a lack of standards to guide the development 
of appropriate play environments.

It is crucial that the arrangement and presence of the tools and implements used by children during play pose the minimum possible risk to avoid situations where outdoor activities cause more harm than good. Sharp objects should not be part of the outside play environment, as children are unfamiliar with the risk that such objects pose. Furthermore, when engaging in practices that are likely to cause harm, such as interacting with strange materials or objects during forest tours, teachers should minimize contact by leading children to safer paths for their protection. In this way, an environment conducive to learning can be realized through the coordination and cooperation of the different stakeholders involved in early childhood development.

Policies should be put in place to guide preschool educators. The authorities tasked with the establishment of outdoor play policies should acknowledge that tutors, children and parents all play a role in adventure activities. Therefore, legislation should be as specific as possible to highlight the involvement of each party in adventure play. The cooperation of all stakeholders is crucial, and parties must agree on and educate each other regarding what is expected to promote learning development and creativity in the context of physical education and other outside play. Based on stakeholders' opinions, policymakers can create a detailed plan that focuses on best teaching practices for positive engagement in outdoor play.

\section{References}

Andrew, A., Attanasio, O., Bernal, R., Sosa, L. C., Krutikova, S., \& Rubio-Codina, M. (2019). Preschool quality and child development (No. w26191). National Bureau of Economic Research. https://doi.org/10.3386/w26191

Bento, G., \& Dias, G. (2017). The importance of outdoor play for young children's healthy development. Porto Biomedical Journal, 2(5), 157-160. https://doi.org/10.1016/j.pbj.2017.03.003

Brussoni, M., Ishikawa, T., Brunelle, S., \& Herrington, S. (2017). Landscapes for play: Effects of an intervention to promote nature-based risky play in early childhood centres. Journal of Environmental Psychology, 139-150. https://doi.org/10.1016/j.jenvp.2017.11.001

Cordiano, T. S., Lee, A., Wilt, J., Elszasz, A., Damour, L. K., \& Russ, S. W. (2019). Nature-based education and kindergarten readiness: Nature-based and traditional preschoolers are equally prepared for kindergarten. International Journal of Early Childhood Environmental Education, 6(3), 18-36. Retrieved from https:/files.eric.ed.gov/fulltext/EJ1225659.pdf

Cortinez-O'Ryan, A., Albagli, A., Sadarangani, K. P., \& Aguilar-Farias, N. (2017). Reclaiming streets for outdoor play: A process and impact evaluation of "Juega en tu Barrio" (play in your neighbourhood), an intervention to increase physical activity and opportunities for play. PloS one, 12(7), e0180172. https://doi.org/10.1371/journal.pone.0180172

Csányi, S. (2018). Developing social interactions through outdoor education in multicultural 
preschool settings: Teachers' perspectives. Retrieved from https:/www.diva-portal.org/smash/get/diva2:1218926/FULLTEXT01.pdf

Davies, L. (2020). Storytelling and nature education. Retrieved from https://www.wildernessawareness.org/articles/storytelling-and-nature-education/

Erdem, D. (2018). Kindergarten teachers' views about outdoor activities. Journal of Education and Learning, 7(3), 203-218. https://doi.org/10.5539/jel.v7n3p203

Ernst, J. (2018). Exploring young children's and parents' preferences for outdoor play settings and affinity toward nature. International Journal of Early Childhood Environmental Education, 5(2), 30-45. https://files.eric.ed.gov/fulltext/EJ1180029.pdf

Frost, J. L., \& Sutterby, J. A. (2017). Outdoor play is essential to whole child development. YC Young Children, 72(3), 82-85. Retrieved from https://openlab.bmcc.cuny.edu/ece-110-lecture/wp-content/uploads/sites/98/2019/11/Frost-Su pperby-2017.pdf

Gardoqui, K., \& Haeger, J. (2020). Outdoor learning strategies and resources for schools and teachers. $\quad$ Retrieved from https://www.greatschoolspartnership.org/outdoor-learning-strategies-and-resources-for-school s-andteachers/?utm_source $=$ rss\&utm_medium $=$ rss\&utm_campaign $=$ outdoor-learning-strategi es-and-resources-for-schools-and-teachers

Garitsis I., Kouthouris C., Zafeiroudi A., \& Alexandris. K. (2010). The effect of 'Green school yards' on environmental awareness, learning, physical, social and mental health of primary school students. Sports \& Recreation Management, 7(2), 19-37.

Gershon, P., \& Pellitteri, J. (2018). Promoting emotional intelligence in preschool education: A review of programs. International Journal of Emotional Education, 10(2), 26-41. https://files.eric.ed.gov/fulltext/EJ1197563.pdf

Gull, C., Goldenstein, S. L., \& Rosengarten, T. (2018). Benefits and risks of tree climbing on child development and resiliency. International Journal of Early Childhood Environmental Education, 5(2), 10-29. https://files.eric.ed.gov/fulltext/EJ1180021.pdf

Harper, N. J. (2017). Outdoor risky play and healthy child development in the shadow of the "risk society": A forest and nature school perspective. Child \& Youth Services, 38(4), 318-334. https://doi.org/10.1080/0145935X.2017.1412825

Hunter, J., Syversen, K. B., Graves, C., \& Bodensteiner, A. (2020). Balancing Outdoor Learning and Play: Adult Perspectives of Teacher Roles and Practice in an Outdoor Classroom. International Journal of Early Childhood Environmental Education, 7(2), 34-50. Retrieved from https://files.eric.ed.gov/fulltext/EJ1254849.pdf

Jui-Feng Weng, Hsiu-lien Kuo, \& Shian-Shyong Tseng (2011). Interactive Storytelling for Elementary School Nature Science Education 11th IEEE International Conference on Advanced Learning Technologies. https://doi.org/10.1109/ICALT.2011.104 
Kaplan. (n.d.). Six outdoor classroom ideas for preschoolers. Retrieved from https://www.kaplanco.com/ii/outdoor-classroom-for-preschoolers

Kaufman, J. C., \& Beghetto, R. A. (2009). Beyond big and little: The four c model of creativity. Review of General Psychology, 13(1), 1-12. https://doi.org/10.1037/a0013688

Kinzie, M. B., Whittaker, J. V., Williford, A. P., De Coster, J., McGuire, P., Lee, Y., Kilday, C. R. (2014). My Teaching Partner-Math/Science pre-kindergarten curricula and teacher supports: Associations with children's mathematics and science learning. Early Childhood Research Quarterly, 29(4), 586-599. https://doi.org/10.1016/j.ecresq.2014.06.007

Kroeker, J. (2017). Indoor and outdoor play in preschool programs. Universal Journal of Educational Research, 5(4), 641-647. https://doi.org/10.13189/ujer.2017.050413

Lindsay, A. C., Greaney, M. L., Wallington, S. F., Mesa, T., \& Salas, C. F. (2017). A review of early influences on physical activity and sedentary behaviours of preschool-age children in high-income countries. Journal for Specialists in Paediatric Nursing, 22(3), e12182. https://doi.org/10.1111/jspn.12182

McClain, C. M. K. (2017). Social contexts of development in natural outdoor environments: Children's motor activities, personal challenges and peer interactions at the river and the creek. http://dx.doi.org/10.1080/14729679.2015.1050682

McClelland, M. M., \& Cameron, C. E. (2019). Developing together: The role of executive function and motor skills in children's early academic lives. Early Childhood Research Quarterly, 46, 142-151. https://doi.org/10.1016/j.ecresq.2018.03.014

McFarland, L., \& Laird, S. G. (2018). Parents' and early childhood educators' attitudes and practices in relation to children's outdoor risky play. Early Childhood Education Journal, 46(2), 159-168. https://doi.org/10.1007/s10643-017-0856-8

Morrissey, A. M., Scott, C., \& Rahimi, M. (2017). A comparison of sociodramatic play processes of preschoolers in a naturalized and a traditional outdoor space. International Journal of Play, 6(2), 177-197. http://dx.doi.org/10.1080/21594937.2017.1348321

Mycock, K. (2020) Forest schools: moving towards an alternative pedagogical response to the Anthropocene?. Discourse: Studies in the Cultural Politics of Education, 41(3), 427-440. https://doi.org/10.1080/01596306.2019.1670446

O’Brien, K. T., Vanderloo, L. M., Bruijns, B. A., Truelove, S., \& Tucker, P. (2018). Physical activity and sedentary time among preschoolers in centre-based childcare: a systematic review. International Journal of Behavioural Nutrition and Physical Activity, 15(1), 1-16. Retrieved from https://ijbnpa.biomedcentral.com/articles/10.1186/s12966-018-0745-6

Rahiem, M. D. (2021). Storytelling in early childhood education: Time to go digital. International Journal of Child Care and Education Policy, 15, 4, 1-20. https://doi.org/10.1186/s40723-021-00081-x

Rennie, L. J., \& McClafferty, T. P. (1996). Science centers and science learning. Studies in 
Science Education, 27, 53-98. https://doi.org/10.1080/03057269608560078

Shepley, C., Lane, J. D., Grisham-Brown, J., Spriggs, A. D., \& Winstead, O. (2018). Effects of a training package to increase teachers' fidelity of naturalistic instructional procedures in inclusive preschool classrooms. Teacher Education and Special Education, 41(4), 321-339. https://doi.org/10.1177/0888406417727043

Sørensen, H. V., \& Birkeland, Å. (2020). Children's explorative activities in kindergarten playgrounds: A case study in China and Norway. In Children's Exploration and Cultural Formation (pp. 47-63). Springer, Cham. https://doi.org/10.3386/w26191

Tandon, P. S., Saelens, B. E., \& Copeland, K. A. (2017). A comparison of parent and childcare provider's attitudes and perceptions about pre-schoolers' physical activity and outdoor time. Child: Care, Health and Development, 43(5), 679-686. https://doi.org/10.1111/cch.12429

Torkar, G., \& Rejc, A. (2017). Children's play and physical activity in traditional and forest (natural) playgrounds. International Journal of Educational Methodology, 3(1), 25-30. https://doi.org/10.12973/ijem.3.1.25

Van Dijk-Wesselius, J. E., Van den Berg, A. E., Maas, J., \& Hovinga, D. (2020). Green Schoolyards as Outdoor Learning Environments: Barriers and Solutions as Experienced by Primary School Teachers. Front. Psychol. 10, 2919. https://doi.org/10.3389/fpsyg.2019.02919

Wojciehowski, M., \& Ernst, J. (2018). Creative by nature: Investigating the impact of nature preschools on young children's creative thinking. International Journal of Early Childhood Environmental Education, 6(1), 3-20. Retrieved from https:/files.eric.ed.gov/fulltext/EJ1193490.pdf

Wright, C., Diener, M.L., \& Kemp, J. L. (2013). Storytelling Dramas as a Community Building Activity in an Early Childhood Classroom. Early Childhood Educ J, 41, 197-210. https://doi.org/10.1007/s10643-012-0544-7

Xu, H., Wen, L. M., Hardy, L. L., \& Rissel, C. (2017). Mothers' perceived neighbourhood environment and outdoor play of 2-to 3.5-year-old children: findings from the healthy beginnings trial. International Journal of Environmental Research and Public Health, 14(9), 1082. https://doi.org/10.3390/ijerph14091082

Y1ldırım, G., \& Akamca, G. Ö. (2017). The effect of outdoor learning activities on the development of preschool children. South African Journal of Education, 37(2). https://doi.org/10.15700/saje.v37n2a1378

Zafeiroudi A., \& Hatzigeorgiadis A. (2008). Environmental awareness, human behavior and participation in outdoor recreation activities. Sports \& Recreation Management, 5(2), 23-40.

Zafeiroudi, A. (2014). Physical Education \& Environmental Education: The Influence of an Outdoor Activities Program on Environmental Responsibility. Inquiries in Sport \& Physical Education, 11(3), 22-35. Retrieved from http://www.pe.uth.gr/emag/index.php/inquiries/article/view/197 


\section{Macrothink}

International Journal of Learning and Development

ISSN 2164-4063 2021, Vol. 11, No. 2

Zafeiroudi, A. (2020). Enhancing Adolescents' Environmental Responsibility Through Outdoor Recreation Activities, Academic Journal of Interdisciplinary Studies 9(6), 43-55. https://doi.org/10.36941/ajis-2020-0110

Zafeiroudi, A., \& Hatzigeorgiadis, A. (2014). The effects of an outdoor pursuit's intervention program on adolescents' environmental beliefs. International Journal on Advances in Education Research, 1(3), 106-118.

\section{Copyright Disclaimer}

Copyright for this article is retained by the author(s), with first publication rights granted to the journal.

This is an open-access article distributed under the terms and conditions of the Creative Commons Attribution license (http://creativecommons.org/licenses/by/4.0/). 